\title{
Fundamentals of Mercury Oxidation in Flue Gas
}

\author{
Technical Annual Report
}

\author{
Reporting Period: \\ August 1, 2005 - July 31, 2006
}

\author{
JoAnn S. Lighty, PI \\ Geoffrey Silcox, co-PI \\ Andrew Fry, Graduate Student \\ Department of Chemical Engineering \\ University of Utah \\ Constance Senior, co-PI \\ Reaction Engineering International \\ Joseph Helble, co-PI \\ Balaji Krishnakumar, Graduate Student \\ Department of Chemical Engineering \\ University of Connecticut \\ Submitted: \\ August 2006 \\ Department of Chemical Engineering \\ 50 South Central Campus Drive \\ Room 3290 MEB \\ University of Utah \\ Salt Lake City, UT 84112
}

DOE Grant Number DE-FG26-03NT41797 


\section{DISCLAIMER}

This report was prepared as an account of work sponsored by an agency of the United States Government. Neither the United States Government nor any agency thereof, nor any of their employees, makes any warranty, express or implied, or assumes any legal liability or responsibility for the accuracy, completeness, or usefulness of any information, apparatus, product, or process disclosed, or represents that its use would not infringe privately owned rights. Reference herein to any specific commercial product, process, or service by trade name, trademark, manufacturer, or otherwise does not necessarily constitute or imply its endorsement, recommendation, or favoring by the United States Government or any agency thereof. The views and opinions of authors expressed herein do not necessarily state or reflect those of the United States Government or any agency thereof. 


\begin{abstract}
The objective of this project is to understand the importance of and the contribution of gas-phase and solid-phase coal constituents in the mercury oxidation reactions. The project involves both experimental and modeling efforts. The team is comprised of the University of Utah, Reaction Engineering International, and the University of Connecticut. The objective is to determine the experimental parameters of importance in the homogeneous and heterogeneous oxidation reactions; validate models; and, improve existing models. Parameters to be studied include $\mathrm{HCl}$, $\mathrm{NOx}$, and $\mathrm{SO}_{2}$ concentrations, ash constituents, and temperature.

This report summarizes Year 3 results for the experimental and modeling tasks. Experiments have been completed on the effects of chlorine. However, the experiments with sulfur dioxide and $\mathrm{NO}$, in the presence of water, suggest that the wet-chemistry analysis system, namely the impingers, is possibly giving erroneous results. Future work will investigate this further and determine the role of reactions in the impingers on the oxidation results. The solid-phase experiments have not been completed and it is anticipated that only preliminary work will be accomplished during this study.
\end{abstract}




\section{TABLE OF CONTENTS}

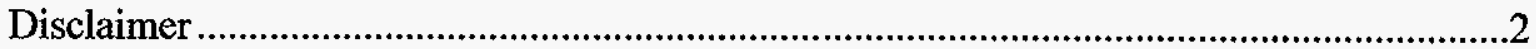

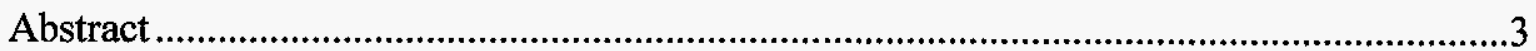

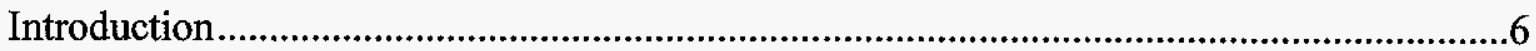

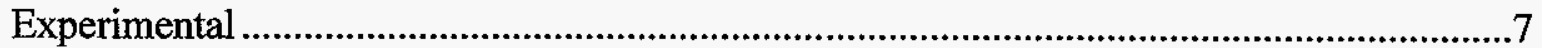

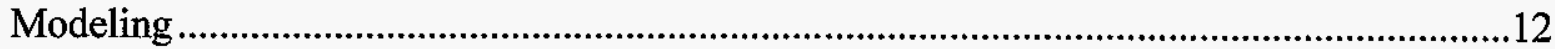

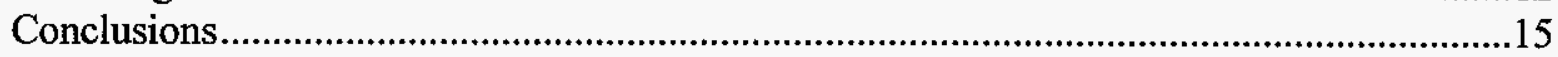

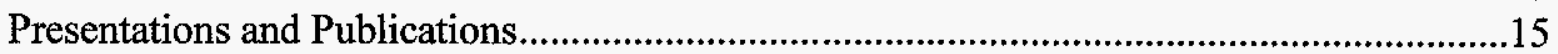

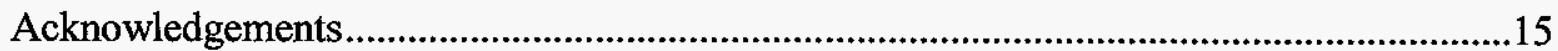

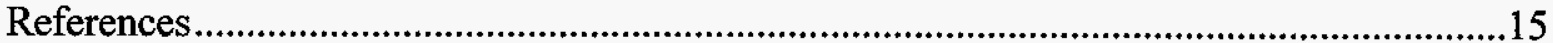




\section{LIST of TABLES and FIGURES}

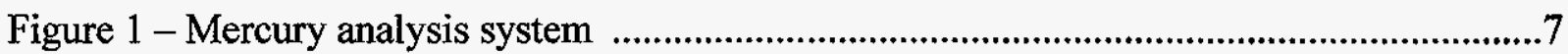

Figure 2 - Experiment versus model effects of NO on mercury oxidation.....................................8

Figure 3 - Experiment versus model effects of $\mathrm{SO}_{2}$ on mercury oxidation ...................................9

Figure 4 - Effects of injecting $\mathrm{NO}$ into $\mathrm{KCl}$ impinger ................................................................10

Figure 5 - Effects of injecting $\mathrm{NO}$ into $\mathrm{SO}_{2}$ impinger ...........................................................11

Figure 6 - Experimental effects of oxygen concentration on mercury oxidation and model

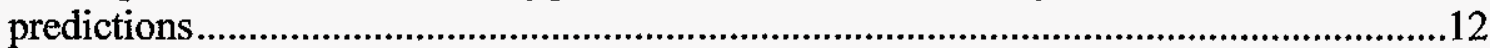

Figure 7 - Temperature profile reported by Fry et al. for the Univ. of UT system .....................13

Figure 8 - Comparison of model predictions with experimental data of Fry et al......................14

Table 1 - Operating Conditions for Univ. of UT Experiments .................................................13 


\section{INTRODUCTION}

The objective of this project is to understand the importance and contribution of gas-phase and solid-phase constituents in the reactions of mercury oxidation. Included in the investigation are the effects of chlorine concentrations, NOx concentration, $\mathrm{SO}_{2}$ concentration, and reactions with ash constituents. A wet flue gas desulphurization system can remove most of the oxidized gaseous mercury in a coal-fired power plant. In addition, oxidized mercury is more likely to adsorb on fly ash, and, hence, be removed by the particulate control device, or be adsorbed by activated carbon. This removal uses existing equipment and requires no additives, making it a low-cost option. However, elemental mercury cannot be removed effectively using these methods. By understanding the important mechanisms in mercury oxidation, a greater fraction of the $\mathrm{Hg}$ could be captured using "back end" technology.

The project team includes the University of Utah, Reaction Engineering International, and the University of Connecticut. The team will collaborate on an experimental and modeling effort that will involve determination of experimental parameters, validation of the model, and improvement of existing models.

Three tasks were envisioned:

\section{Task 1.0 - Experimental Investigation of Mercury Chemistry}

The University of Utah will perform natural gas and coal combustion experiments in both a mercury reactor (Phase 1) and a facility with realistic time/temperature histories (Phase 2). The experiments will utilize "doped" constituents to investigate the importance of these constituents in the mercury oxidation mechanism. Both gas ( $\mathrm{HCl}, \mathrm{NOx}$, and $\mathrm{SO} 2$ ) and solid (e.g. iron, calcium) constituents will be investigated.

\section{Task 2.0-Model Validation}

REI and UConn will use existing versions of mercury oxidation models in the flue gas to guide the experimental design, predicting ranges of process parameters, e.g. temperature, chlorine concentration, and nitrogen oxide concentration, which would produce measurable changes in mercury speciation. UConn will focus on mechanism development; REI will focus on modeling and interpretation of experiments. The experimental data will be used to validate the gas-phase oxidation model (and improve it, if needed). The data will also clearly identify the effects of heterogeneous oxidation, as distinct from homogeneous oxidation. This information will be used to validate and improve heterogeneous models for mercury oxidation on fly ash.

\section{Task 3.0 - Evaluation of Control Strategies}

The effectiveness of mercury control strategies varies depending on the speciation of mercury in the flue gas. As a result of the experimental and model validation activities, we will be better able to predict the speciation of mercury in flue gas for a wide range of coal types and conditions. We will use this information to recommend modifications to existing control strategies or to suggest new control strategies, if they arise. 
Previous results have focused on developing an experimental system which is reliable and without bias for gas-phase mechanism validation. These studies have included understanding the effects of the reactor and sampling system. Further work was done on the effects of sulfur dioxide and NO which have led us to believe that some of the observed oxidation occurred within the impingers, not the reaction system. Future work will focus on verification of the wetchemistry system with the hope of determining the role of the impinger chemistry in our results, which could be extended to the work of others. In addition, dispersed-phase experiments will be run on coal ash constituents, including iron and calcium. Unburned carbon may also be a candidate once other major constituent heterogeneous interactions are understood.

\section{EXPERIMENTAL}

\section{Mercury Reactor Furnace and Mercury Analyzer}

The mercury reactor used in this study has been detailed in previous reports and in Fry, et al. (2006). The reactor has been fitted with a natural gas, premixed burner. In these experiments all reactants are introduced through the burner and pass through the flame.

A sample of flue gas is withdrawn from the bottom of the reactor and enters the sampleconditioning system, designed by Southern Research Institute (SRI). In this system the sample gas is pulled in two streams directly from the last section of the quartz reaction tube into a set of conditioning impingers. One stream is bubbled through a solution of stannous chloride to reduce oxidized mercury species to elemental mercury. The stream then contacts a solution of sodium hydroxide to remove acid gases. This stream represents the total mercury concentration in the reactor. The second stream is first treated with a solution of potassium chloride to remove oxidized mercury species and then is also treated in a caustic solution for acid gas removal. This stream is representative of the elemental mercury concentration in the reactor. Oxidized mercury species are represented by the difference between total and elemental mercury concentrations. Water is removed from the sample gas by a chiller and then each stream is intermittently sent to the analyzer by a valve box connected to the analyzer. Analysis is performed using a Tekran 2537A mercury vapor analyzer. The system, previously reported, is shown in Figure 1.

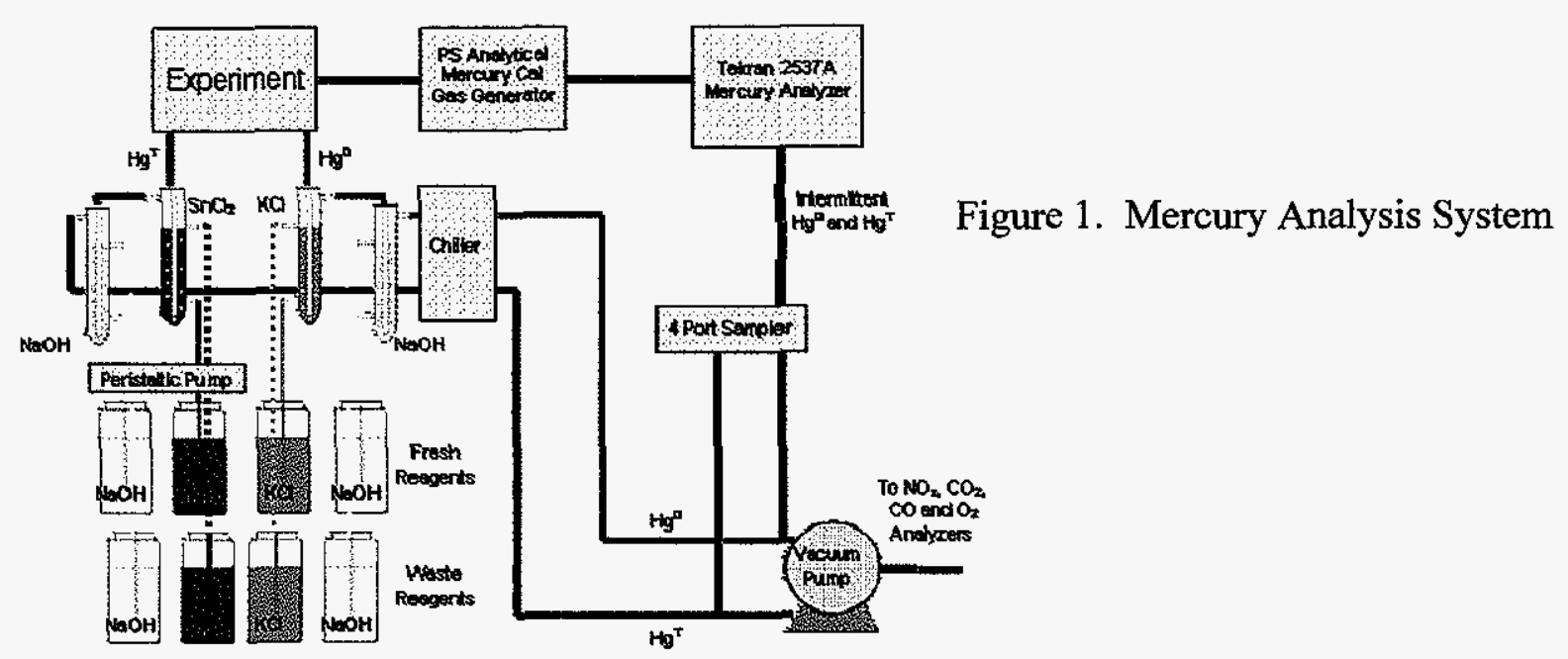


Experiments were conducted with the addition of $\mathrm{NO}$ and $\mathrm{SO}_{2}$ into the burner. Pure NO was provided to the system by a lecture bottle using a $0-6 \mathrm{ml} / \mathrm{min}$ rotameter flow tube and a high resolution valve. NO concentrations in the flue gas were measured using a California Analytical Instruments, Model ZRF CO / $\mathrm{NO}$ analyzer. $\mathrm{SO}_{2}$ concentrations were controlled by injecting a standard of $\mathrm{SO}_{2}$ in air.

The NO concentration generated by the quartz glass burner while operated at nominal conditions was 36 ppmv, dry. NO concentrations of 100,250 and 500 ppmv, dry were produced upon the addition of $\mathrm{NO}$ to the burner. $\mathrm{Cl}_{2}$ was injected into the burner to produce reactor chlorine concentrations (as $\mathrm{Cl}$ ) of $0-600 \mathrm{ppmv}$. The oxidation curves (i.e., percent mercury oxidized versus input chlorine) generated from this set of experiments are presented in Figure 2. In addition, modeling of the experimental conditions was performed and model results are also presented for comparison in Figure 2. The experimental data show that, at a $\mathrm{Cl}$ concentration of 200 ppmv and 500 ppmv NO the oxidation is $28.2 \%$, denoting a reduction in oxidation at these conditions of $44 \%$. This result is similar to that found by Sterling, et al. (2004). They reported a $30 \%$ decrease in homogeneous mercury oxidation with the introduction of $300 \mathrm{ppmv}$ NO and essentially no effect when $100 \mathrm{ppmv}$ NO was introduced at all chlorine concentrations. The model predicted essentially no effect of NO on mercury oxidation at all NO and chlorine concentrations.

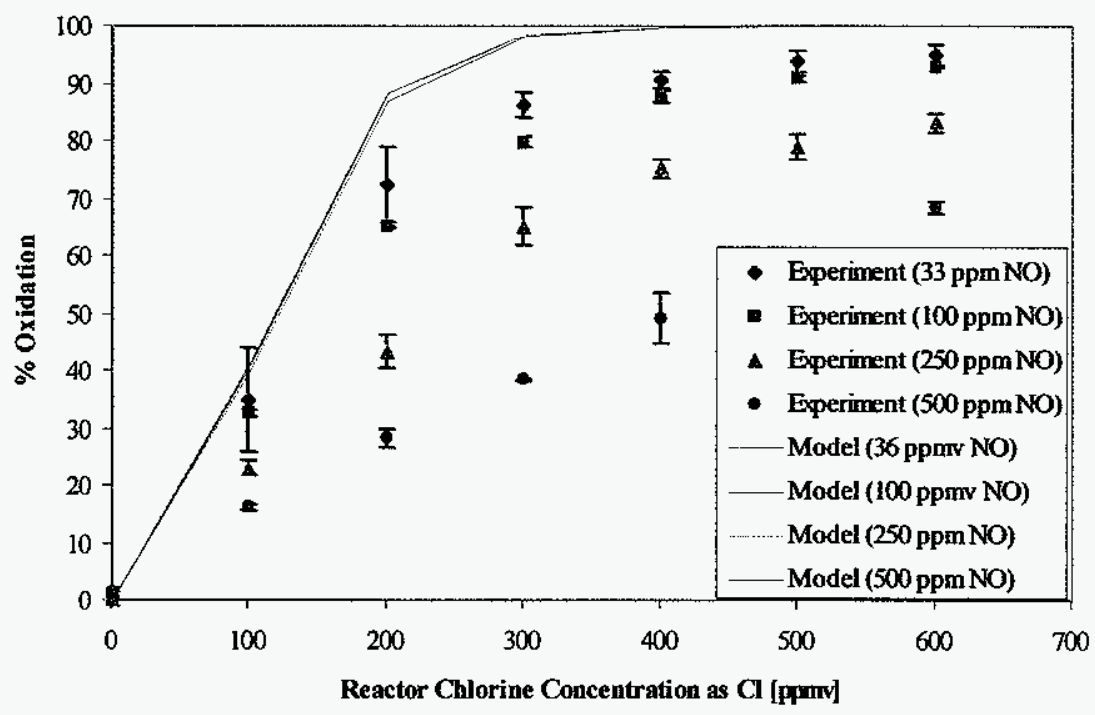

Figure 2. Experiment vs. Model Effects of NO on Mercury Oxidation

$\mathrm{SO}_{2}$ was introduced into the quartz burner from the $\mathrm{SO}_{2}$ calibration gas standard in air using a Brooks 5850E mass flow controller. For this set of experiments the concentration of $\mathrm{SO}_{2}$ was not measured, but was calculated by mass balance. The $\mathrm{SO}_{2}$ concentration in the reactor was set at $300 \mathrm{ppmv}$ and the chlorine concentration (as atomic $\mathrm{Cl}$ ) was varied from 0 to $600 \mathrm{ppmv}$. 
Mercury oxidation for each of these conditions was measured and is presented in Figure 3. The data for mercury oxidation with no $\mathrm{SO}_{2}$ are presented for comparison.

The introduction of $300 \mathrm{ppmv} \mathrm{SO}_{2}$ results in a $68 \%$ reduction of mercury oxidation. Sterling and co-workers (2004) reported a reduction in mercury oxidation of $44 \%$ with a concentration of $\mathrm{SO}_{2}$ at $400 \mathrm{ppmv}$ and an initial $\mathrm{Cl}_{2}$ concentration of $250 \mathrm{ppmv}$ (or $500 \mathrm{ppmv}$ of total chlorine as $\mathrm{Cl}$ ). The impact of $\mathrm{SO}_{2}$ in the current investigation is significantly greater. The model was again used to predict the effects of $\mathrm{SO}_{2}$ on mercury oxidation for the conditions of interest. Results from this modeling effort are presented in the figure for comparison to the experimental results. The model predicts that $\mathrm{SO}_{2}$ affects the concentrations of certain free radical species that promote oxidation of elemental mercury by chlorine compounds. Through this interaction a reduction in oxidation is observed, but much less than that shown in the experimental results.

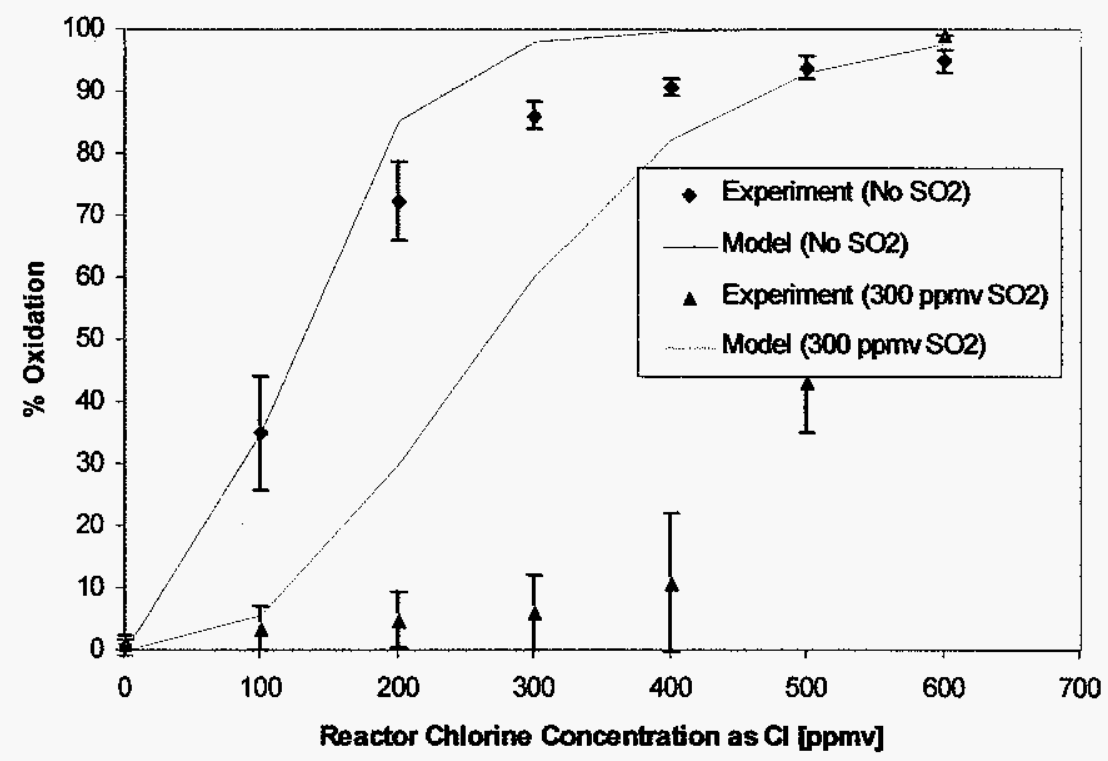

Figure 3. Experiment vs. Model Effects of $\mathrm{SO}_{2}$ on Mercury Oxidation

We were surprised to see the difference between the data and the model, given that previous model predictions were quite close to the experimental results. Before looking at the model and detailed kinetics, we wanted to confirm the experimental findings. To do this, we started by directly injecting the $\mathrm{NO}$ and $\mathrm{SO}_{2}$ in the impingers to ensure that we did not have any effects within the impinger system.

For these experiments, the reactor was operated with a chlorine concentration of $200 \mathrm{ppmv}$ (with reactor chlorine as $\mathrm{Cl}$ ), producing mercury oxidation of nearly $80 \%$. Elemental mercury measurements were taken with a modified conditioning system. In this case, the conditioning system was modified to inject $\mathrm{NO}$ and $\mathrm{SO}_{2}$ directly one the $\mathrm{KCl}$ impinger. The $\mathrm{SnCl}_{2}$ solution was removed from the conditioning system and replaced by a second solution of $10 \% \mathrm{KCl}$, resulting in two redundant measurements of elemental mercury. Therefore, the impingers should be measuring the amount of elemental mercury in the system without regard to the total mercury. 
The data for NO are shown in Figure 4. In this case, the NO was injected into the system and then turned off. Initially, the amount of injected elemental mercury is analyzed as the total amount of mercury in both impingers ("Control" being a $\mathrm{KCl}$ impinger and "NO" being a $\mathrm{KCl}$ impinger with NO injected into it). Initially, the two flows were not equal, resulting in a difference between the two systems (see 10:19:12 to 11:31:12). As this was adjusted, the two measurements were equal. As $\mathrm{NO}$ was injected into the $\mathrm{KCl}$ impinger, there was an increase in the measured concentration of elemental mercury, an apparent reduction in mercury oxidation. This was representative of $28.6 \%$ oxidation for the conditions of $200 \mathrm{ppmv} \mathrm{Cl}$ and $500 \mathrm{ppmv}$ NO. Once the NO was removed, elemental mercury concentration went back to the concentrations of the "Control" case, indicating about $80 \%$ oxidation.

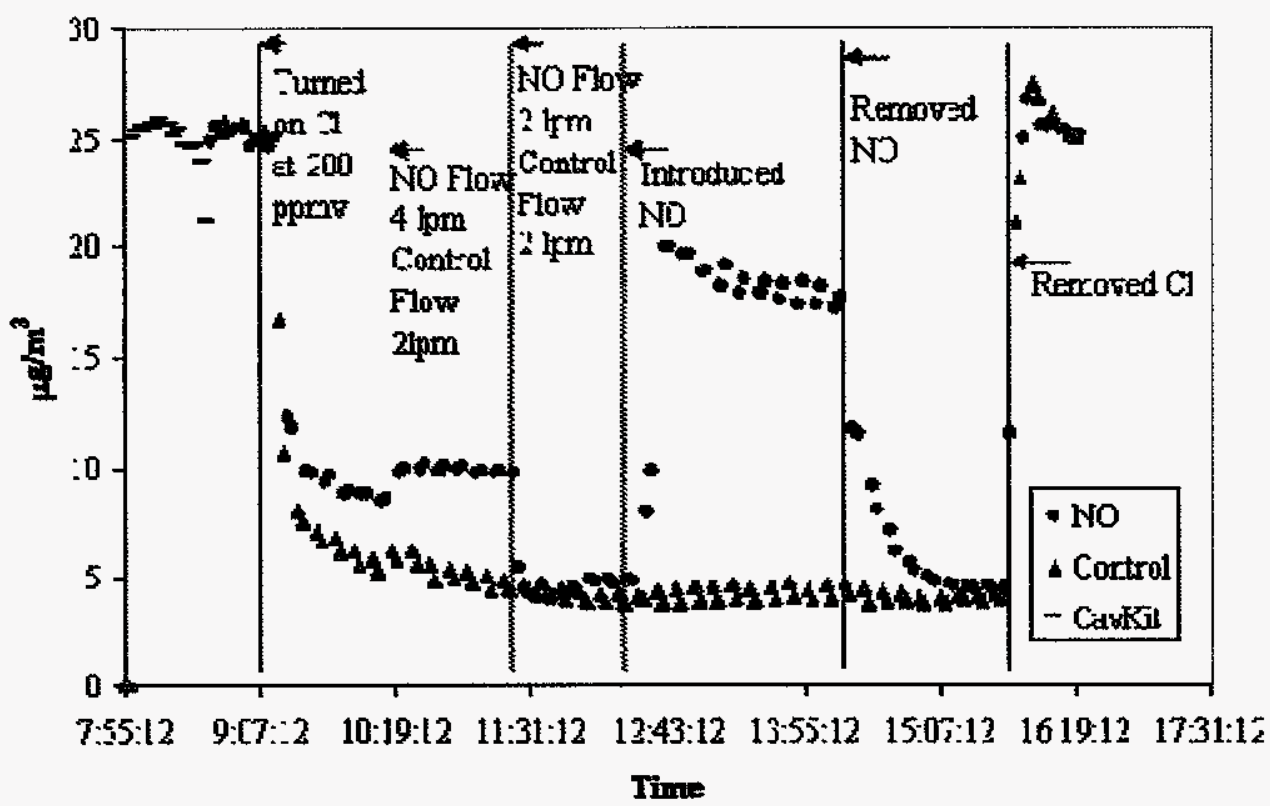

Figure 4. Effects of Injecting NO into $\mathrm{KCl}$ Impinger

Identical experiments were performed to elucidate the effects of injecting pure $\mathrm{SO}_{2}$ into the $\mathrm{KCl}$ impinger. The reactor was operated with a $\mathrm{Cl}$ concentration of 200 ppmv, again providing mercury oxidation of nearly $80 \% . \mathrm{SO}_{2}$ was injected into the impinger at the valve settings found to produce a concentration of $300 \mathrm{ppmv}$ in the $\mathrm{KCl}$ impinger. Data from this experiment are presented in Figure 5. Mercury measurements for the sample stream with the $\mathrm{SO}_{2}$ injection are labeled " $\mathrm{SO}_{2}$ " and the standard sample stream is again labeled "Control". In this experiment the two sample streams were not reporting exactly the same value of elemental mercury. This is most likely a result of residual $\mathrm{SO}_{2}$ in the impinger from the previous $\mathrm{SO}_{2}$ mass balance experiment. At the point when $300 \mathrm{ppmv} \mathrm{SO}_{2}$ was introduced into the " $\mathrm{SO}_{2}$ " impinger all of the mercury in the system was reported as elemental in this stream. When the $\mathrm{SO}_{2}$ was removed, the amount oxidized mercury went back to $80 \%$. 


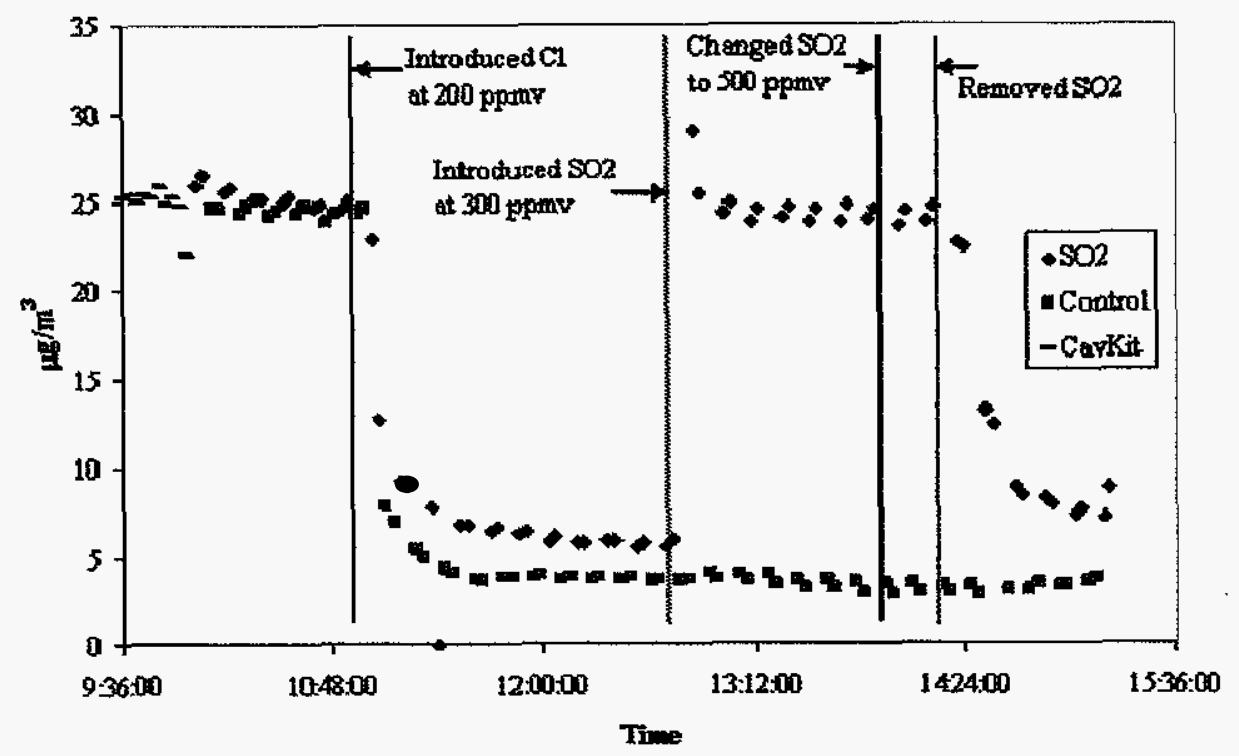

Figure 5. Effects of Injecting $\mathrm{SO}_{2}$ into $\mathrm{KCl}$ Impinger

For conditions of $200 \mathrm{ppmv} \mathrm{Cl}$ and 500 ppmv NO, oxidation of $28.6 \%$ was observed when the NO was injected directly into the impinger and $28.2 \%$ when NO was injected into the flame. These data indicate that all of the reduction in mercury oxidation was occurring in the $\mathrm{KCl}$ impinger, relative to the amount of oxidation in the experiments with chlorine only. Model results confirm that these observed effects of NO are not occurring in the reactor due to gasphase reactions. Impinger experiments also show that $300 \mathrm{ppmv} \mathrm{SO}_{2}$ in the $\mathrm{KCl}$ impinger reduced all oxidized mercury to elemental. Similar results were found when the $\mathrm{SO}_{2}$ was injected into the burner.

These results have led us to question the role of the $\mathrm{KCl}$ impinger. In the absence of $\mathrm{NO}$ and $\mathrm{SO}_{2}$, it appears as though $\mathrm{HOCl}$ is being formed in the $\mathrm{KCl}$ impinger, via the reaction:

$$
\mathrm{Cl}_{2}+2 \mathrm{H}_{2} \mathrm{O}=\mathrm{HOCl}+\mathrm{H}_{3} \mathrm{O}^{+}+\mathrm{Cl}^{-}
$$

The $\mathrm{HOCl}$ in turn oxidizes the elemental mercury; hence the appearance of oxidation without the $\mathrm{NO}$ and $\mathrm{SO}_{2}$ additions, but limited oxidation under those conditions. The work of (Linak et al. 2001) from EPA indicates that these interactions could be limited by the addition of sodium thiosulfate. Presently, we are studying these reactions to determine the issue with regard to the wet sampling system. As yet, no conclusions have been drawn, especially in light of the model predictions matching the experimental data in the absence of $\mathrm{NO}$ and $\mathrm{SO}_{2}$. Consistent with our experiments, good agreement between the model and experimental data from UConn was also demonstrated previously by Qiu et al. 
Previous mercury oxidation experiments were performed at a measured $\mathrm{O}_{2}$ concentration of $0.88 \%$ exceeding the expected value of $0.46 \%$. To compare data collected at different $\mathrm{O}_{2}$ concentrations and to infer oxidation behavior at $\mathrm{O}_{2}$ concentrations representative of coal combustion flue gas, experiments and model predictions were performed. Experiments spanned a range of $\mathrm{O}_{2}$ concentrations from 0 to $3 \%$ with one fuel rich experiment. These data are presented in Figure 6 and show little or no dependence of oxidation on $\mathrm{O}_{2}$ concentration at concentrations above zero.

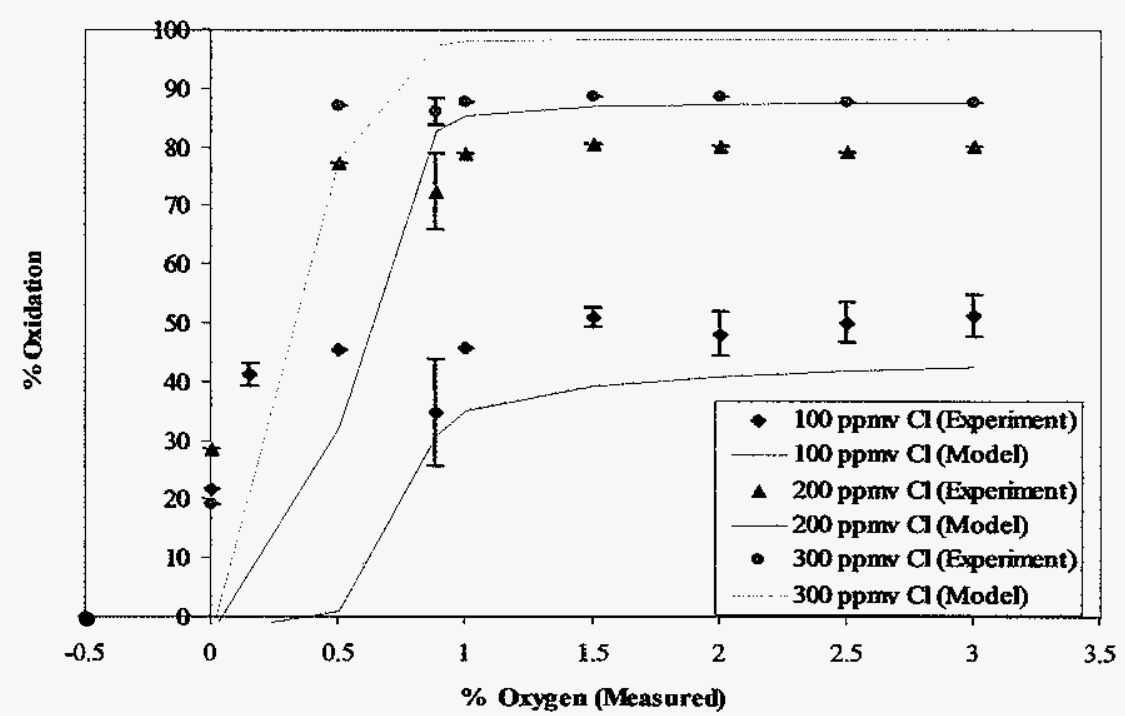

Figure 6. Experimental Effects of Oxygen Concentration on Mercury Oxidation and Model Predictions

\section{MODELING}

The majority of the homogenous $\mathrm{Hg}$ rate constants reported in the literature have been based on hard-sphere collision limits and/or empirical data-fitting procedures. Recently, rate constants developed using theoretical methods such as quantum chemistry and transition state theory have been reported (Wilcox et al. 2004). Wilcox et al. provide theoretical rate constant estimates for the following seven reactions:

$$
\begin{aligned}
& \mathrm{Hg}+\mathrm{Cl}+\mathrm{M}=\mathrm{HgCl}+\mathrm{M} \\
& \mathrm{Hg}+\mathrm{Cl}_{2}=\mathrm{HgCl}+\mathrm{Cl} \\
& \mathrm{Hg}+\mathrm{HCl}=\mathrm{HgCl}+\mathrm{H} \\
& \mathrm{Hg}+\mathrm{Cl}_{2}+\mathrm{M}=\mathrm{HgCl}_{2}+\mathrm{M} \\
& \mathrm{HgCl}+\mathrm{Cl}+\mathrm{M}=\mathrm{HgCl}_{2}+\mathrm{M} \\
& \mathrm{HgCl}+\mathrm{HCl}=\mathrm{HgCl}_{2}+\mathrm{H} \\
& \mathrm{HgCl}+\mathrm{Cl}_{2}=\mathrm{HgCl}_{2}+\mathrm{Cl}
\end{aligned}
$$

Although the reaction sequence above does not consider $\mathrm{Hg}$ oxidation mediated by $\mathrm{HOCl}$, it clearly accounts for the major channel of $\mathrm{Hg}$ oxidation by $\mathrm{Cl}$. The $\mathrm{HOCl}$ reactions are 
potentially as important as those of $\mathrm{Cl}_{2}$ and $\mathrm{HCl}$, which have been found to be less important than the $\mathrm{Cl}$ reaction. To evaluate these theoretical rate constants, the above $\mathrm{Hg}$ reaction sequence was coupled to the sub-models elucidating $\mathrm{Cl}, \mathrm{NO}_{\mathrm{x}}$, and $\mathrm{SO}_{\mathrm{x}}$ chemistry as assembled from literature by Helble and co-workers (Qiu et al. 2003) as part of the University of Connecticut (UConn) subcontract to this project. This overall reaction mechanism scheme is referred to as 'Wilcox Hg-UConn' mechanism.

Data from the Utah experimental system (Fry et al. 2005) were used to evaluate the model predictions of the Wilcox Hg-UConn mechanism. The predictions using the original UConn mechanism are also presented for comparison with those of Wilcox $\mathrm{Hg}$ reaction rates. A summary of the experimental conditions is presented in Table 1.

Table 1. Operating conditions for Univ. of UT experiments

\begin{tabular}{cccc}
\hline Case & Quench $(\mathrm{K} / \mathrm{s})$ & Residence time (s) & Initial temperature (K) \\
\hline I & Low $(\sim 220)$ & 7 & 1120 \\
II & High $(\sim 440)$ & $\sim 8$ & 1060 \\
\hline
\end{tabular}

The temperature profile for both these cases is reported in literature (Fry et al.) and is reproduced in Figure 7. In both the cases, the post-combustion flue gas temperature increased to approximately $1400 \mathrm{~K}$ prior to the controlled quench. The system was modeled as a plug flow reactor (PFR) starting with an equilibrium composition calculated at $1100 \mathrm{~K}$ corresponding to the burner stoichiometry. The equilibrium predicted concentration of NO $(38.2 \mathrm{ppmv})$ at this temperature also agreed well with the reported value of $38 \mathrm{ppmv}$. The remainder of the reported temperature profile was implemented without any modifications. 


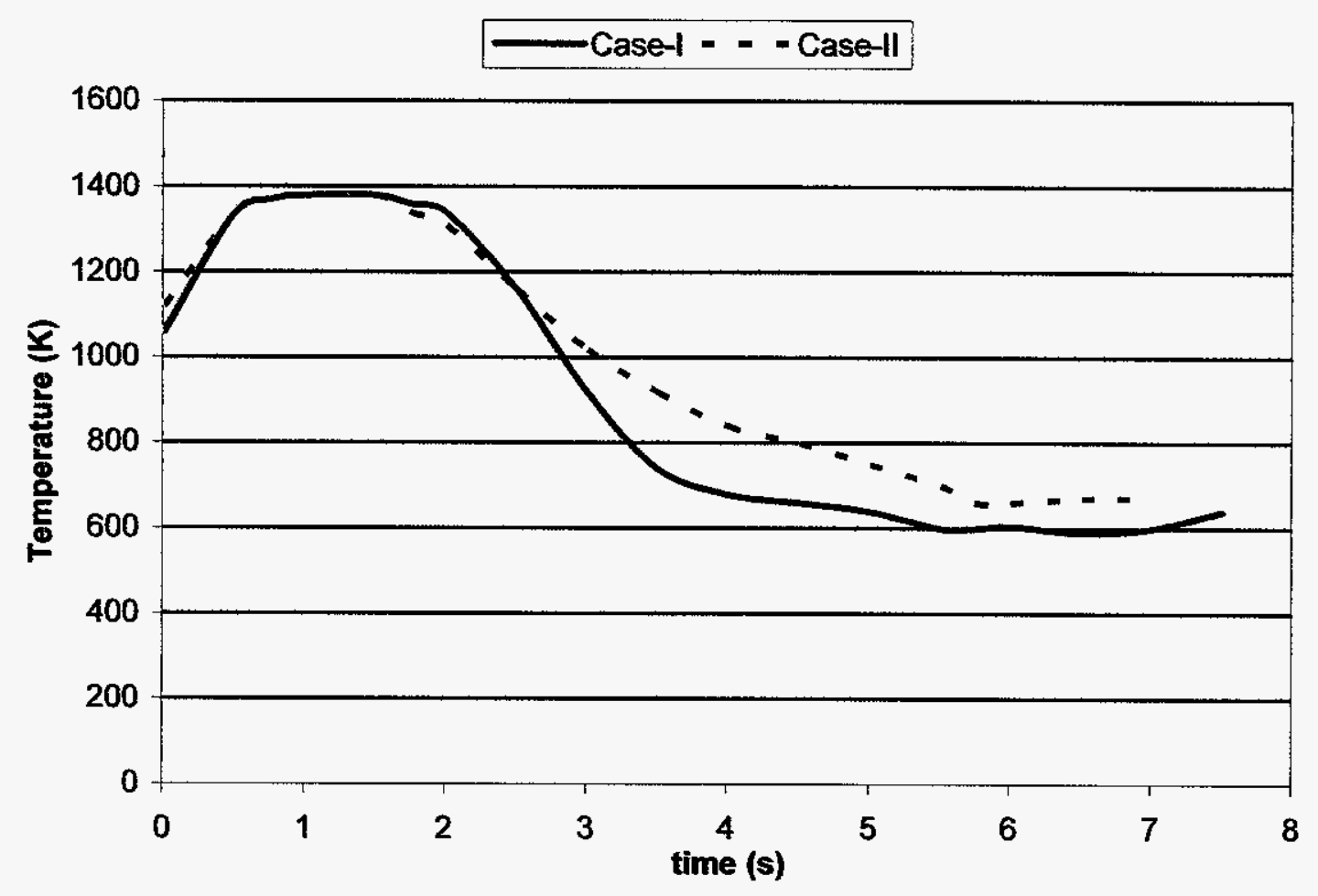

Figure 7: Temperature profile reported by Fry et al. for the Univ. of UT system

The model predictions using the UConn and the Wilcox Hg-UConn mechanisms are compared against the experimental data in Figure 8. Recall that the difference in the two models is the $\mathrm{Hg}$ reaction scheme alone and the corresponding rate constants.

At quench rates of $220 \mathrm{~K} / \mathrm{s}$ (Case-I), the UConn mechanism predicts $\mathrm{Hg}$ oxidation accurately over the entire range of chlorine concentrations, however, at faster quench rates of $440 \mathrm{~K} / \mathrm{s}$ (Case-II), there is greater divergence from the data. The scatter is especially high at lower chlorine concentrations $(<400 \mathrm{ppmv})$. Both mechanisms predict greater oxidation at the higher quench rate, in agreement with the data. In fact, this is the only trend that is predicted by the Wilcox Hg-UConn mechanism. The most significant discrepancy with the theoretical reaction parameter set is that the predictions are insensitive to $\mathrm{Cl}$ concentration. For the two quench rates, the Wilcox $\mathrm{Hg}$-UConn mechanism predicts on average 35 and $77 \%$ oxidation across $100-700$ ppmv $\mathrm{HCl}$ suggesting that this scheme, in its present form, is inadequate to model the experimental system. One of the factors for the discrepancies in the Wilcox-derived reaction scheme could be the absence of any $\mathrm{Hg}$ interactions with $\mathrm{HOCl}$, though such reactions are generally believed to have only a secondary influence in comparison to $\mathrm{Cl} / \mathrm{Cl}_{2}$. 


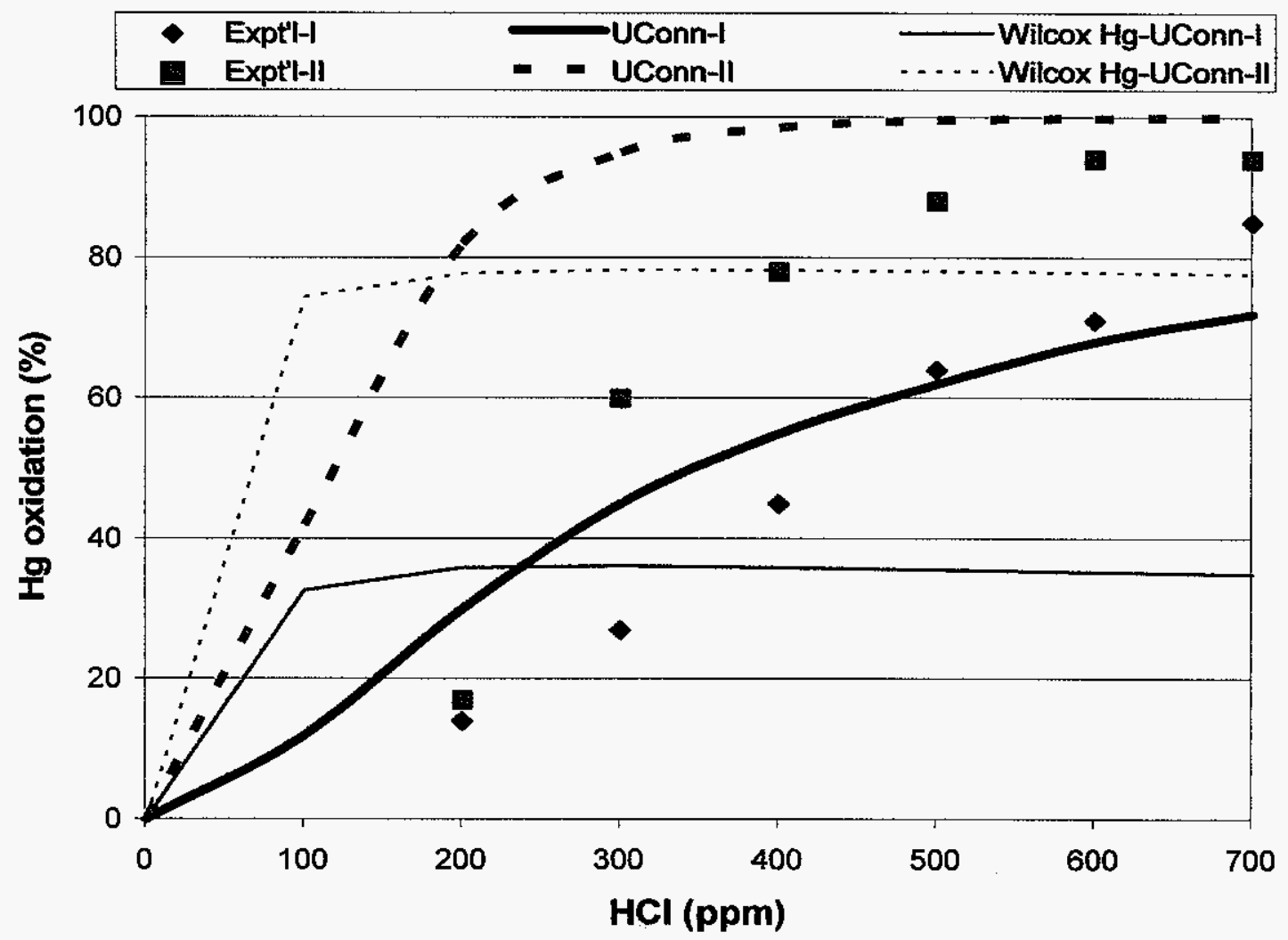

Figure 8: Comparison of model predictions (UConn and Wilcox Hg-UConn) with experimental data of Fry et al.

\section{CONCLUSIONS}

The accomplishments during the third year have included:

- Experimental runs investigating the role of $\mathrm{NO}$ and $\mathrm{SO}_{2}$.

- Experiments and modeling regarding the role of oxygen.

During this next year, we will continue to investigate the effects of $\mathrm{NO}$ and $\mathrm{SO}_{2}$ and their role in the impinger chemistry. If the oxidation is occurring in the impingers, adjustments to the model will be necessary since the predictions did match the data. In addition we will begin disperse phase experiments on coal constituents, namely iron and calcium.

\section{PRESENTATIONS and PUBLICATIONS}

A. Fry, B. Cauch, G. D. Silcox, J. S. Lighty, "Experimental evaluation of the effects of quench rate and quartz surface area on homogeneous mercury oxidation," accepted to the $31^{\text {st }}$ International Symposium on Combustion, Heidelberg, Germany (2006). 
A. Fry, J. Lighty, G. Silcox, and B. Cauch, "Experimental Study of Homogeneous Mercury Oxidation Reactions Designed to Facilitate Model Development and Mechanism Validation," International Conference on Air Quality, Arlington, VA, September 2005.

C. L. Senior, A. Fry, J. S. Lighty, G. D. Silcox, "Detailed kinetic modeling of homogeneous mercury oxidation reactions in a $1000 \mathrm{Btu} / \mathrm{hr}$ quartz furnace, presented at $22^{\text {nd }}$ Annual International Pittsburgh Coal Conference, Pittsburgh, PA, September 2005.

\section{ACKNOWLEDGEMENTS}

This annual report was prepared with the support of the U.S. Department of Energy, under Award No. DE-FG26-03NT41797. However, any opinions, findings, conclusions, or recommendations expressed herein are those of the authors and do not necessarily reflect the views of the DOE.

\section{REFERENCES}

Fry, A.R.; Lighty, J.S.; Silcox, G.D. 2005. Proc. $30^{\text {th }}$ International Technical Conf. on Coal Utilization \& Fuel Systems, April.

Linak W. P. et al., 2001. J. Air \& Waste Manage. Assoc., 51, p. 688.

Qiu, J.; Helble, J.J.; Sterling, R., 2003, Proc. $12^{\text {th }}$ International Conf. on Coal Sci. Cairns, Australia, November.

Sterling, R. O.; Qiu, J.; Helble, J. J. 2004, 18th Annual ACERC Technical Conference, Provo, Ut, February 12 .

Wilcox, J., 2004. "On the Path to Elucidating the Speciation of Mercury in the Flue Gases of Coal Combustion", $\mathrm{PhD}$ Thesis, University of Arizona. 